\title{
DESCRIÇÃO E ANÁLISE DO PROCESSO DE FORMAÇÃO DE UMA REDE DE COOPERATIVAS DE CATADORES DE MATERIAIS RECICLÁVEIS: CASO DA REDE ANASTÁCIA, ESTADO DE SÃO PAULO
}

\author{
DESCRIPTION AND ANALYSIS OF THE FORMATION PROCESS OF A WASTE PICKER \\ COOPERATIVE NETWORK: REDE ANASTÁCIA CASE, STATE OF SAO PAULO, BRAZIL
}

DESCRIPCIÓN Y ANÁLISIS DEL PROCESO DE FORMACIÓN DE UNA RED DE COOPERATIVAS DE RECOLECTORES DE MATERIALES RECICLABLES: EL CASO DE LA REDE ANASTÁCIA EN EL ESTADO DE SAO PAULO, BRASIL

\author{
Alexandra Savio \\ Mestranda em Engenharia Urbana, UFSCar, Brasil \\ alexandra.savio@yahoo.com.br
}

Bernardo A. Do N. Teixeira Professor Doutor, UFSCar, Brasil. bernardo@ufscar.br 


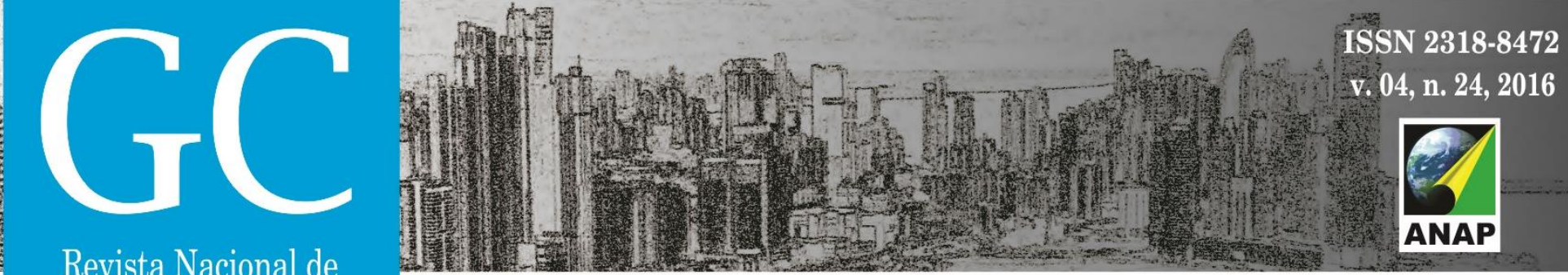

Gerenciamento de Cidades

vias urbanas (GUTIERREZ PEPINELLI, 2013), ou de forma organizada através de associações e cooperativas.

De acordo com dados do Movimento Nacional dos Catadores de Materiais Recicláveis - MNCR (2014), os catadores são responsáveis por $89 \%$ de todo o trabalho da cadeia da reciclagem que é formada por eles, intermediários (sucateiros/aparistas) e indústrias recicladoras. Porém, a partir da Figura 1 observa-se que os catadores são os que menos recebem na cadeia de reciclagem, pois a remuneração pelos materiais vendidos possui menor valor agregado. Deste modo, as indústrias recicladoras, seguida dos intermediários, são os que conseguem maior rentabilidade em todo o processo.

Além das dificuldades financeiras, os catadores enfrentam ambientes e condições precárias de trabalho e embora desenvolvam uma atividade de importância ambiental, deparam-se com muitas adversidades como a informalidade, violência, invisibilidade, exclusão social, discriminação, exposição a riscos, ausência de contratos e garantias trabalhistas, adoecimento, exploração de mão de obra e baixo rendimento (OLIVEIRA, 2011).

Com o intuito de melhorar a participação destes trabalhadores na cadeia da reciclagem, algumas legislações foram publicadas afim de fortalecer e estruturar estes grupos (SILVA; GÓES; ALVAREZ, 2013).

Dentre as principais legislações, a PNRS traz alguns destaques como em seus instrumentos Art. 8o "o incentivo à criação e ao desenvolvimento de cooperativas ou de outras formas de associação de catadores de materiais reutilizáveis e recicláveis". O Artigo 18 prevê que a prioridade no acesso aos recursos da União serão os municípios que "implantarem a coleta seletiva com a participação de cooperativas ou outras formas de associação de catadores de materiais reutilizáveis e recicláveis formadas por pessoas físicas de baixa renda". Por fim, o Artigo 42 menciona que poderá instituir medidas indutoras e linhas de financiamento para atender às iniciativas de implantação de infraestrutura física e aquisição de equipamentos para cooperativas ou outras formas de associação de catadores de materiais reutilizáveis e recicláveis formadas por pessoas físicas de baixa renda.

O pagamento por serviços prestados pelos catadores aos municípios brasileiros é uma reivindicação histórica do MNCR e uma das primeiras cidades a considerarem este pagamento pelos serviços de coleta seletiva foi a cidade de Diadema. Este município passou a remunerálos por tonelada de resíduos recuperados com o mesmo valor para as empresas de coleta comum (MNCR 2012).

Outro exemplo de apoio aos catadores é o Decreto № 7.405, de 23 de dezembro de 2010, que institui o Programa Pró-Catador. Este programa tem a finalidade de integrar e articular as ações voltadas ao apoio e fomento à organização produtiva dos catadores, através da capacitação; formação; assessoria técnica; incubação de cooperativas e empreendimentos sociais solidários; responsabilidade compartilhada; aquisição de equipamentos e adaptação de infraestrutura física; organização de redes de comercialização e cadeias produtivas integradas por cooperativas e associações. 
Quando os catadores trabalham em grupos organizados, observa-se que há a construção da identidade como uma categoria profissional, assim como o pertencimento a um grupo, a uma classe. Com isso, há possibilidade de estabelecer vínculos mais sólidos com a sociedade na construção de parcerias, prestação de serviços e também pode ser alvo de investimentos por parte de empresas e instituições na geração de renda e melhorias socioambientais (MOTA, 2005).

Portanto, a mudança do quadro de exploração atual dos catadores só se modificará com adoção de estratégias econômicas, políticas e sociais nas esferas municipais, estaduais e federais. Assim sendo, uma das saídas seria concentrar a oferta de materiais recicláveis em redes de organizações de catadores capazes de recuperar uma quantia de material que seja suficiente participar no mercado, negociando preços e condições justos com as indústrias (PINHEL, 2013).

Para Inojosa (1999), uma rede em princípio é parceria que pode promover relações interpessoais, interorganizacionais, intergovernamentais e intersetoriais e, com isso, articular famílias, pessoas físicas, pessoas jurídicas, organizações públicas e/ou organizações privadas e até mesmo estados.

No início dos anos 60 no Brasil, começaram a surgir a organização dos movimentos sociais em rede, através dos atores políticos democráticos contra a ditadura, em busca da democratização e luta pelos direitos humanos. No entanto, apenas a partir do início dos anos 90, com o uso de sistemas de comunicação a distância através do computador, que a articulação em rede obteve uma nova dimensão e um reconhecido papel político na conquista dos direitos sociais no país (MARTINHO, 2003).

Dentre os diversos tipos de redes, há aquelas de colaboração solidária, que tem por objetivo integrar empreendimentos solidários de produção, comércio, serviços e consumo, organizações sociais diversas, com finalidade de fortalecer e reorganizar as cadeias produtivas (MANCE, 2005).

Conforme define Crúzio (2006),

As cooperativas em rede podem construir alianças sociais e políticas, obter em seus negócios internos e externos, eliminar a subordinação funcional e reduzir a estrutura organizacional ao negócio essencial a cada uma. No que tange à construção de alianças sociais e políticas, as cooperativas em rede podem superar com mais eficácia seus problemas econômicos, tanto internos quanto externos. Internamente, as cooperativas aderentes à rede podem articular e definir objetivos organizacionais coletivamente, respeitando a autonomia e a diferença de cada uma. Externamente, podem responder às demandas sociais ou necessidades das comunidades nas quais se encontram, diante dos governos municipal, estadual e federal.

Deste modo, "redes são sistemas organizacionais capazes de reunir indivíduos e instituições, de forma democrática e participativa, em torno de objetivos e/ou temáticas comuns" (HERMAN, 2011 p. 74). 


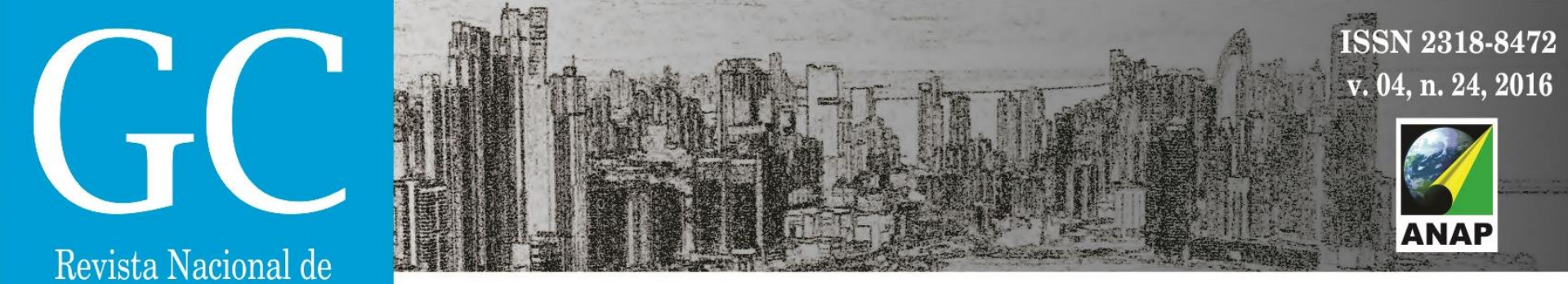

Gerenciamento de Cidades

No Brasil já existem algumas redes de cooperativas de catadores de materiais recicláveis, especificamente no Estado de São Paulo são observados alguns exemplos conforme Quadro 1. Tais informações referem-se ao local/área de abrangência, município onde está localizada a sede da rede, número de cooperativas filiadas e ano de início das atividades.

\begin{tabular}{|c|c|c|c|c|}
\hline Rede & Localização/área de abrangência & Sede Rede & $\begin{array}{l}\text { Número de } \\
\text { Cooperativas }\end{array}$ & Ano Início \\
\hline CATA-VIDA & $\begin{array}{l}\text { Alumínio; Capão Bonito; } \\
\text { Itapetininga; Itararé; Piedade; Pilar } \\
\text { do Sul; Salto do Pirapora; } \\
\text { São Miguel Arcanjo; Sorocaba. }\end{array}$ & Alumínio & 18 & 2001 \\
\hline CATA-SAMPA & $\begin{array}{l}\text { Arujá; Biritiba Mirim; Salesópolis; } \\
\text { Ferras de Vasconcelos; Guarulhos; } \\
\text { Itanhaém; Mongaguá; Poá; Santa } \\
\text { Isabel; Santos; São Paulo. }\end{array}$ & Mogi das Cruzes & 17 & 2006 \\
\hline COOPCENT-ABC & $\begin{array}{l}\text { Diadema; Mauá; Ribeirão Pires; } \\
\text { Rio Grande da Serra; Santo André; } \\
\text { São Bernardo do Campo; São } \\
\text { Caetano do Sul. }\end{array}$ & Diadema & 12 & 2007 \\
\hline RECICLAMP & Campinas e Valinhos. & Campinas & 06 & 2008 \\
\hline CATAVALE & $\begin{array}{l}\text { Aparecida; Guaratinguetá; Jacareí; } \\
\text { Pindamonhangaba; São José dos } \\
\text { Campos; São Vicente. }\end{array}$ & $\begin{array}{c}\text { São José dos } \\
\text { Campos }\end{array}$ & 8 & 2011 \\
\hline VERDE SUSTENTÁVEL & $\begin{array}{l}\text { Cotia; Embu Das Artes; Francisco } \\
\text { Morato; Itapevi; Jandira; Osasco; } \\
\text { Santana Do Parnaíba; São Paulo; } \\
\text { Tabuão Da Serra. }\end{array}$ & Cotia & 13 & 2013 \\
\hline UNIR & Campinas. & Campinas & 4 & 2013 \\
\hline COOPERCOP & Assis e Ourinhos. & Assis & 9 & 2013 \\
\hline REDE PAULISTA & $\begin{array}{lrl}\text { Capão } & \text { Redondo; } & \text { Carapicuíba; } \\
\text { Osasco; São Paulo. } & \\
\end{array}$ & São Paulo & 7 & 2013 \\
\hline ANASTÁCIA & $\begin{array}{l}\text { Araraquara; Leme; Morro Agudo; } \\
\text { Orlândia; Piracicaba; Ribeirão } \\
\text { Preto; Rio Claro; São Carlos. }\end{array}$ & Orlândia & 8 & 2016 \\
\hline
\end{tabular}

Fonte: Elaborado pelos autores a partir de CARVALHO, 2013; SG/PR, 2014; CEADEC, 2016; CIRANDAS, 2016; COOPCENT-ABC, 2016; CRCA EDH, 2016; LADEIA, 2015; REDE ANASTÁCIA, 2016; REDE CATASAMPA, 2016; REDE PAULISTA, 2016; SMETAL, 2016.

A primeira rede de catadores de materiais recicláveis a ser criada no país foi a Rede Cata-Vida (VIANA, 2012). Surgiu na região de Sorocaba, inicialmente em 1999, com as primeiras articulações frente às dificuldades que tinham em comercializar os materiais recicláveis coletados na região, pois não conseguiam acumular volume suficiente para vender diretamente para as empresas recicladoras. Em 2001, os empreendimentos começaram a comercializar conjuntamente alguns tipos de materiais e no Encontro Regional de Catadores do mesmo ano, a rede foi criada. Nos primeiros anos, a mesma contava apenas com infraestrutura e equipamentos das próprias cooperativas, mas com a busca de parcerias por meio de projetos, conseguiram em 2008 iniciar o processo de verticalização da coleta seletiva 
Em relação aos resíduos coletados, os municípios com maiores quantidades são Ribeirão Preto e Piracicaba. Isto deve-se ao fato de serem as cidades com maior número de habitantes, sendo 658.059 e 388.412 , respectivamente.

Um resumo dos assuntos discutidos e encaminhados nas reuniões realizadas pela Rede Anastácia no período de maio/2015 a julho/2016 foram sistematizados no Quadro 3.

Quadro 3: Resumo dos principais assuntos discutidos e encaminhados nas reuniões da Rede Anastácia.

\begin{tabular}{|c|c|c|}
\hline Data & $\begin{array}{l}\text { Número de } \\
\text { Cooperativas } \\
\text { Participantes }\end{array}$ & Principais assuntos discutidos e encaminhados \\
\hline $13 / 05 / 2015$ & 11 & $\begin{array}{l}\text { Validação do Conselho Gestor da rede; checagem de documentação para Projeto Cataforte } \\
\text { III. }\end{array}$ \\
\hline $17 / 06 / 2015$ & 10 & $\begin{array}{l}\text { Discussão sobre o 6o Encontro Regional da Coleta Seletiva Solidária organizada e realizada } \\
\text { pela Rede Anastácia; esclarecimento sobre as etapas do Projeto Cataforte III. }\end{array}$ \\
\hline 15/07/2015 & 8 & $\begin{array}{l}\text { Elaboração de uma Moção de Apoio da rede para encaminhar à Prefeitura de São Carlos, } \\
\text { devido às dificuldades que a Coopervida estava enfrentando; apresentação de uma } \\
\text { cooperada sobre algumas reflexões sobre a rede (identidade da rede, estrutura } \\
\text { organizativa, comunicação entre os empreendimentos, mobilização dos cooperado, } \\
\text { relação política interna e externa e como será o monitoramento e avaliação das ações da } \\
\text { rede). }\end{array}$ \\
\hline 09/09/2015 & 9 & $\begin{array}{l}\text { Apresentação da criação de um site para rede, feito por uma das cooperadas; últimos } \\
\text { acertos sobre a realização do } 6 \text { o Encontro Regional da Coleta Seletiva Solidária e } \\
\text { mobilização para a participação das catadoras no } 1 \text { o Encontro Das Mulheres Catadoras do } \\
\text { Estado de São Paulo em Osasco nos dias } 25 \text { e 26/09/2015. }\end{array}$ \\
\hline $17 / 02 / 2016$ & 7 & $\begin{array}{l}\text { Apresentação do contador da rede sobre a elaboração do Plano Contábil; aprovação de } \\
\text { parte dos itens propostos para o Estatuto Social da Rede Anastácia. }\end{array}$ \\
\hline 09/03/2016 & 6 & $\begin{array}{l}\text { Finalização da aprovação dos itens do Estatuto Social, onde o documento era lido em voz } \\
\text { alta e os cooperados iriam esclarecendo dúvidas e sugerindo alterações. }\end{array}$ \\
\hline $14 / 04 / 2016$ & 8 & $\begin{array}{l}\text { Discussão sobre o andamento do Cataforte III, o qual naquele momento não havia } \\
\text { nenhuma movimentação em relação ao projeto e liberação de verba para as Redes. Com } \\
\text { isso, elaboraram uma carta solicitando esclarecimentos para encaminhar aos responsáveis } \\
\text { pela gestão do projeto. }\end{array}$ \\
\hline $13 / 05 / 2016$ & $15^{*}$ & $\begin{array}{l}\text { Aprovação em Assembleia Direta da constituição e formalização em cartório da Rede } \\
\text { Anastácia; neste dia, } 8 \text { cooperativas se filiaram a rede e posteriormente foi realizada a } \\
\text { eleição do Conselho Administrativo e Fiscal da rede. }\end{array}$ \\
\hline $15 / 06 / 2016$ & 9 & $\begin{array}{l}\text { Debate sobre o Plano de Negócios da Rede e as possibilidades de comercialização conjunta } \\
\text { entre as cooperativas, assim como a prestação de serviços relacionados a logística reversa. }\end{array}$ \\
\hline $29 / 06 / 2016$ & 8 & $\begin{array}{l}\text { Discussão sobre o Plano Contábil que está sendo realizado pela rede e seus objetivos no } \\
\text { Cataforte; debate sobre as questões contábeis e tributárias das cooperativas e como } \\
\text { adequá-las às legislações vigentes. }\end{array}$ \\
\hline 28/07/2016 & 8 & $\begin{array}{l}\text { Discussão de alguns problemas que estão ocorrendo com as cooperativas, como falta de } \\
\text { local para as atividades e contrato com as prefeituras pela coleta seletiva. Com isso, foi } \\
\text { debatido formas de mobilização da rede para apoiar estas cooperativas e uma delas foi } \\
\text { elaborar uma "carta de compromisso" para ser entregue aos candidatos às prefeituras dos } \\
\text { municípios, para que eles garantam que tomarão providencias a estes problemas assim } \\
\text { que assumirem o cargo de prefeitos em 2017. }\end{array}$ \\
\hline
\end{tabular}

Fonte: OS AUTORES, 2016

* Neste dia participaram além das cooperativas que já faziam parte da Rede Anastácia informalmente, também outras cooperativas ou redes de cooperativas de catadores de materiais recicláveis: Catasampa, Sempre Verde, Recicla Catanduva, Acomar, Corserta, Futura, Jacareí Recicla. 
CARVALHO, J. M. G. Estudo sobre processo de formação da rede de cooperativas de catadores de materiais recicláveis do Vale do Paraíba - Estado de São Paulo. Dissertação (Mestrado - Programa de Pós-Graduação em Ciência Ambiental) - Universidade de São Paulo, São Paulo, 2013.

CEADEC - CENTRO DE ESTUDOS E APOIO AO DESENVOLVIMENTO EMPREGO E CIDADANIA. A rede solidária catavida. Disponível em: <http://www.ceadec.org.br/index.php?pagina=catavida\&cv=carta>. Acesso em: 01 ago. 2016.

CEMPRE - COMPROMISSO EMPRESARIAL PARA RECICLAGEM. Coleta seletiva ainda é um desafio para o país, aponta ciclosoft 2016. Disponível em: <http://cempre.org.br/cempre-informa/id/70/coleta-seletiva-ainda-e-um-desafiopara-o-pais--aponta-ciclosoft-2016>. Acesso em: 30 jul. 2016.

CIRANDAS. Fórum Brasileiro de Economia Solidária. Rede Cata-Vida: Qualificar, fortalecer e empoderar. Disponível em: http://cirandas.net/redesolidariacata-vida/blog. Acesso em: 06 mai. 2016.

COOPCENT ABC - COOPERATIVA CENTRAL DO ABC. Nossa história. Disponível em: <http://www.coopcentabc.org.br/?pg=nossa_historia>. Acesso em: 01 ago. 2016.

CRCA EDH - 10 ANOS UNIDOS PELA CIDADANIA. Cooperativas Incubadas e Assessoradas pelo CRCA. Disponível em: <http://www.10anoscampinasrecicla.crca.org.br/coop_crca.htm>. Acesso em: 01 ago. 2016.

CRÚZIO, H. O. Cooperativas em rede e autogestão do conhecimento: o trabalho flexível em torno de processos, sob habilidades e equipes. Rio de Janeiro: Editora FGV, 2006. 176 p.

FRANKENBERG, C.L.C.; RAYA-RODRIGUES, M.T.; CANTELLI, M. Gerenciamento de resíduos e certificação ambiental. Porto Alegre: EDPUCRS, 2000.

FERNANDES, F. M. B. Considerações Metodológicas sobre a Técnica da Observação Participante. In MATTOS, R. A.; BAPTISTA, T. W. F. Caminhos para análise das políticas de saúde, 2011. p. 262-274.

GIL, A. C. Métodos e técnicas de pesquisa social. 5. ed. São Paulo: Atlas, 1999.

GUTIERREZ PEPINELLI, R. F. Empreendimentos econômicos solidários de catadores: cadeias produtivas de resíduos, processos tecnológicos e parcerias. 2013. 181 p. Dissertação (Mestrado em Ciência, Tecnologia e Sociedade) Centro de Educação e Ciências Humanas, Universidade Federal de São Carlos, São Carlos, 2011.

HERMANN, I. L. Empreendedorismo: livro didático. 3. ed. Palhoça: UnisulVirtual, 2011.

IBGE - Instituto Brasileiro de Geografia e Estatística. Cidades. Brasília: Ministério do Planejamento, Orçamento e Gestão, 2016. Disponível em: http://cidades.ibge.gov.br. Acesso em: 11 mai. 2016.

INOJOSA, R. M. Redes de compromisso social. Revista de Administração Pública, Rio de Janeiro, v. 33, n. 5, p. 115141, set./out. 1999.

LADEIA, C. R.; ROCHA, S. R. C.; CARVALHO, A. M. R. Espaços de articulação política entre empreendimentos de catadores. In: Congresso de Pesquisadores em Economia Solidária, 1. 2015, São Carlos. Anais ... São Carlos: Diagrama Editorial, 2015. Disponível em <http://www.conpes.ufscar.br/anais>. Acesso em: 23 ago. 2016.

MANCE, E. A. A revolução das redes de colaboração solidaria. Encontro Internacional de Economias Salesianas, Espanha, 2005.

MARTINHO, Cássio. Redes: uma introdução às dinâmicas da conectividade e da auto-organização. 1 ed. Brasília - DF: WWF-Brasil, 2003. $91 \mathrm{p}$. 
Revista Nacional de

VIANA, R. C. G. Rede Solidária Cata-Vida: construindo a sustentabilidade dos empreendimentos econômicos solidários dos catadores de materiais recicláveis na região de Sorocaba/SP. Inc. Soc., Brasília, v. 6 n. 1, p.78-83 jul./dez. 2012.

ZANIN, M.; TEIXEIRA, B. A. N. Articulação de Cooperativas de Catadores: Aspectos Fomentadores de Rede. I CONPES - Congresso de Pesquisadores de Economia Solidária, 2015, São Carlos, SP. Anais do I CONPES. São Carlos: ABPES, 2015. v. 1. p. $1-12$ 